\title{
A Pragmatist Explanation of Technical Capabilities in Nonhuman Animals
}

Ana Cuevas-Badallo

\section{OpenEdition}

1 Journals

\section{Electronic version}

URL: http://journals.openedition.org/ejpap/2324

DOI: 10.4000/ejpap.2324

ISSN: 2036-4091

\section{Publisher}

Associazione Pragma

\section{Electronic reference}

Ana Cuevas-Badallo, "A Pragmatist Explanation of Technical Capabilities in Nonhuman Animals", European Journal of Pragmatism and American Philosophy [Online], XIII-1 | 2021, Online since 02 April 2021, connection on 04 April 2021. URL: http://journals.openedition.org/ejpap/2324 ; DOI: https:// doi.org/10.4000/ejpap.2324

This text was automatically generated on 4 April 2021.

\section{$(\mathbb{D \Theta \Theta}$}

Author retains copyright and grants the European Journal of Pragmatism and American Philosophy right of first publication with the work simultaneously licensed under a Creative Commons AttributionNonCommercial-NoDerivatives 4.0 International License. 


\title{
A Pragmatist Explanation of Technical Capabilities in Nonhuman Animals
}

\author{
Ana Cuevas-Badallo
}

\section{AUTHOR'S NOTE}

I would like to thank the anonymous referees for carefully reading the manuscript and for giving such constructive comments which substantially helped improving the quality of the paper.

\section{Introduction}

1 There are at least two strategies to understand the specific characteristics of human beings. The most common is to emphasize those features that are unique to the species: capabilities such as consciousness and self-awareness, knowledge of the mental states of others, sense of humor, sense of history or the future, language, intentionality, personality, capacity to develop a culture, or the capability to make artifacts (Glock 2008: 160). Such characteristics are unique to humans, and are generally considered a point of superiority over other species. This attitude of emphasizing singularity, and superiority as a consequence of that singularity, has revealed an anthropocentric bias, common among philosophers and scientists alike.

2 A different approach to analyzing human capabilities, less common, although not without its illustrious proponents (for instance, Charles Darwin) has been to analyze the degree to which these characteristics are already present in other species. That is, singularity, if such a thing exists, does not derive from exclusivity, but depends on the degree to which those capacities are present in different species. The argument is based 
on the understanding that those capabilities come from adaptive and evolutionary mechanisms.

3 This paper explores the second strategy in analyzing a capability that has long been considered unique to humans: the ability to manufacture and use artifacts. Don Ihde and Lambros Malafouris, in a recent work (2019), espouse the consideration of human beings as Homo faber, and point out that human beings are not unique in this capacity, although they emphasize the complexity of the technical systems that humans build. Other species efficiently transform their environment by creating and using artifacts. The strategy employed here is grounded in classical pragmatism. Classical pragmatists such as Chauncey Wright, Charles S. Peirce, and especially John Dewey, combined enactivist interpretations with the thesis of gradual continuity in nature (or synechism, to use Peirce's terminology).

4 The first section of the paper briefly presents Ihde and Malafouris's enactivist explanation of human technical capabilities. The second describes Dewey's notion of experience and his naturalistic and gradualistic attitude. The third presents some contemporary perspectives on nonhuman animals' "tool using" in the fields of ethology and philosophy. The last section explores the possibility of extending Dewey's explanation to other species as technical agents. His notion of experience combines the enactivist viewpoint with evolutionary gradual continuity, and both can untangle some explanatory problems related to the characterization of those objects created by species other than humans. Nonhuman animals develop different strategies to cope with their changing and challenging environments. Among those evolutionary strategies, some modify their environment with objects used or created for technical purposes. Obviously, not all objects used or manufactured by a nonhuman animal are technical artifacts - otherwise, even the air they breathe or the nourishment they ingest would be considered a technical artifact. However, restricting the creation of technical artifacts to humans only, discounting every object used or created by another species, is arguably an anthropocentric thesis.

\section{Ihde and Malafouris' Homo faber and Enactivism}

Ihde and Malafouris (2019) point out the need to assert Bergson's consideration of human beings as Homo faber:

Our emphasis falls specifically on the human predisposition for technological embodiment and creativity. We re-approach the notion Homo faber in a way that, on the one hand, retains the power and value of this notion to signify the primacy of making or creative material engagement in human life and evolution and, on the other hand, reclaims the notion from any misleading connotations of human exceptionalism (other animals make and use tools). (Ihde \& Malafouris 2019: 195)

Ihde and Malafouris base their approach on two theses: the Postphenomenology that Ihde has espoused throughout his career, and the Material Engagement Theory developed by Malafouris. They emphasize the human predisposition toward "technological embodiment" (Ihde 1990) and "creative material engagement" (Malafouris 2014, 2015), as well as the varieties of skill, praxis and self-consciousness (Ihde 2009; Malafouris 2008, 2014, 2015). Ihde and Malafouris point out that humans change the environment through technology, and through that change, in turn, humans also are transformed: "humans more than just adapting to their environments are also actively changing them (for better or worse), initiating new complex co- 
evolutionary paths and biosocial synergies" (Ihde \& Malafouris 2019: 196). They suggest, as Bergson did before them, that humans change their own conditions and their evolution through material transformation. The main difference between humans and other species that also change their environment and create and use artifacts is "the special place that fabrication and material culture has in human life and evolution. Wherever technics originated, it is clear that humans expanded and multiplied the interaction" (ibid.: 197). While they insist that those capabilities to use and create artifacts are not unique to humans, "to various degrees, all animals are niche constructors and some of them are prolific users of tools" (ibid.), the amount and variety of technical relationships that humans are able to create is comparatively huge (ibid.: 200). According to Ihde and Malafouris, the difference lies in the fact that "humans are self-conscious fabricators that become (ontogenetically and phylogenetically) through their creative engagement with the material world. Other tool-using animals are not self-conscious fabricators and they do not become by making; they merely manipulate material objects in an extractive foraging context and in predominantly utilitarian fashion" (ibid.). In addition to self-consciousness, intentionality is another characteristic that distinguishes humans from other animals: not only because intentionality refers to the capacity to make plans or represent, but "because of the way human intentional states are directly embodied and realised in the hybrid space of situated action" (ibid.: 201).

7 Nonetheless, Ihde and Malafouris do not consider these mental capabilities the cornerstone in distinguishing between humans and other animals that create and use artifacts. An enactivist approach can be used to explore how different forms of materiality affect the bodies and senses of different animals, and why those animals, with their specific physical structures, "invoke or afford certain ways of engaging and using specific forms of materiality" (ibid.: 202). Enactivism is used to understand how humans and other animals technically relate to the environment. However, Ihde and Malafouris' interpretation exclusively emphasizes the human side and leaves the door open to examine how other species relate technically to their environment. The sections below explore that strategy, attempting to show how other species use and create artifacts, suggesting some differences and similarities with human beings. For that purpose, I will use recent discoveries from ethology that show other species' abilities and capacities to make and use tools, as well as an enactivist point of view. Rather than taking Bergson as a reference, I use Dewey's pragmatism and his naturalist, gradualist, and non-dualist philosophy. I will delve into the different adaptive strategies that other species use, to showcase the differences between them. It does not seem appropriate to put all these strategies into one broad set, where all species and their creations are separated from the creations of humans, as the interpretations of ethology and philosophy have suggested.

\section{Naturalism and Enactivism in Dewey's Pragmatism}

8 This section explores an extension of Dewey's approach to nonhuman animals as technical agents. There are several reasons to employ Dewey's philosophy to analyze the capabilities of nonhuman animals to make and use artifacts: his anti-dualism, manifested in his enactivist conception of cognition (Gallagher 2017: 48, 50), as well as his naturalized and evolutionary perspective on living beings. Dewey, with his notions 
of "experience," "perception," "problematic situation," "habit" and "inquiry," was probably the philosopher who developed that perspective in a deeper way. Several studies have recently linked enactive and extended conceptions of cognition with classical pragmatism (Gallagher 2009, 2014, 2017; Fabbrichesi 2016). While it is emphasized that enactivism has its roots in phenomenology, there are very few mentions of pragmatists like Peirce, Mead and Dewey who developed very similar ideas. For instance, the relation that Dewey defended in his philosophy between cognition and action, or his criticism of the "spectator theory," are common also in enactivism.

9 Another good reason to use Dewey's approach is that he can be considered the first philosopher of technology that was "interested in constructing a new form of naturalism that would take into account continuities within nature[;] he looked for a way to define technology with sufficient breadth" (Hickman 2009: 51).

10 Last but not least, Dewey's view that human cognition is always socially situated will help us understand why technological artifacts made by humans and artifacts made by nonhuman animals are often classified into different categories. Recent discoveries about peculiarities in human cognition seem to uphold Dewey's view about the relevance of the social and cultural construction of technological capabilities and knowledge.

11 As Trevor Pearce argues in a recent book, "pragmatism - the most famous movement in American philosophy in the early 1900s - was the outgrowth of a rich conversation between late ninetieth-century philosophers, biologists, and social scientists. For pragmatists like Du Bois and Dewey, biological ideas such as evolution, adaptation, and environment were central to debates about scientific inquiry, social reform, and moral progress" (Pearce 2020: 3). Actually, Dewey was one of the first philosophers to recognize the implications of Darwin's theory: not only a new way of thinking about life and the situation of human beings in nature, but also a different approach to philosophy (Popp 2012: xi). In this new philosophical strategy, human beings, their experiences, capabilities and dispositions, must be understood in continuity with the rest of living beings: "the idea of eternally fixed species gave way to the idea of temporal organisms caught up in the continual changes required of them in order that they might come to terms with their respective (and continually changing) environments" (Hickman 1990: 31-2). This line of continuity with other biological beings opens the door to a new interpretation of experience. In Dewey's philosophy, experience becomes a way of dealing with things: before knowing about something it is necessary to have experiences with those things: i.e., knowing how is previous to knowing that (Kalpokas 2010: 182).

In "The Need for a Recovery of Philosophy," Dewey summarizes his main criticisms of the traditional conception of experience, and simultaneously presents his own perspective. In Dewey's view, experience is: (i) regarded as "the intercourse of a living being with its physical and social environment"; (ii) not a subjective, but an "objective world which enters into the actions and suffering of men and undergoes modification through their responses"; (iii) experimental, an effort to change what is taken as given: "it is characterized by projection, by reaching forward into the unknown; connection with a future is its salient trait"; (iv) "undergoing of an environment and a striving for its control in new directions is pregnant with connections"; and (v) when it is conscious, it is full of inference (Dewey 1917/1998: 61). Just a few lines later, Dewey considers the contribution of biology to his idea of experience: 
Any account of experience must now fit into the consideration that experiencing means living; and that living goes on in and because of an environing medium, not in a vacuum. Where there is experience, there is a living being. Where there is life, there is a double connection maintained with the environment. In art, environmental energies constitute organic functions; they enter into them. [...] Growth and decay, health and disease, are alike continuous with activities of the natural surroundings. The difference lies in the bearing of what happens upon future life activity. From the standpoint of this future reference environmental incidents fall into groups: those favorable-to-life activities and those hostile. (Ibid:: 61-2)

Dewey emphasizes two theses: naturalism and evolutionism. Organisms are active in the environment, they act in their environing medium, changing it and changing themselves in the process: "adjustment to the environment means not passive acceptance of the latter, but acting so that the environing changes take a certain turn" (ibid.: 62). Experience is a matter of doings and sufferings - a process of continuous adjustment. Thus, again from the Darwinian perspective, active experience is a strategy for survival, and human beings are problem-solving animals. In Dewey's own words: "The first great consideration is that life goes on in an environment, not merely in it, but because of it, through interaction with it" (Dewey 1934/2005: 12).

Experience connects perception and action. There is not a spectator who perceives the external world and forms an internal (subjective) conception of it. As long as human beings have evolved in a changing environment, they have been, and are, agents within the world; they are part of it. A spectator theory of knowledge is replaced by an operational conception of knowledge: "In the orthodox view, experience is regarded primarily as a knowledge affair. But to eyes not looking through ancient spectacles, it assuredly appears as an affair of the intercourse of a living being with its physical and social environment" (Dewey 1917/1998: 6).

On the other hand, agents (not only humans) experience the world as possibilities for action, and knowledge is the result of two experienced situations: "the present situation here and now and the future situation that is an outcome of some way of acting" (Määttänen 2015: 12). The environment is not equivalent to the situation, but for an environment to become a situation an agent has to experience it as such: situations are constituted by the organism and the environment. Something may be a situation for one agent but not for another. Being in a situation usually involves several possibilities of action, and this is where the notions of problematic situation and inquiry appear on the scene. When the agent faces a problematic situation, in the first instance, it only perceives and acts, but if the action does not solve the situation, then the normal situation becomes an occasion for inquiry. The agent starts to inquire, and during the inquiry, the experience changes and becomes part of the agent's knowledge, available for use in addressing future problematic situations. The agent transforms the problematic situation into a different, more comprehensible one. Dewey, influenced by Peirce, who emphasized the role of resistance to hard facts as objective conditions of action, believed agents use physical and cognitive tools to deal with problematic situations.

As the agent accumulates experiences and ways of dealing with difficult situations, habits are formed. Habits are not permanently fixed, but change and are updated through the perception of new problematic situations and the action carried out by the agent. The agent can use those habits for similar situations in "schematically 
structured sequences of acts" (Määttänen 2015: 33). The schematic structures do not need to be propositional; they do not need to be expressed in a language. As long as they ensure some success for the agent, habits are reinforced. Habit formation for Dewey, as it was for Peirce, is a form of reasoning, the most basic way of experiencing, and it helps the agent to anticipate and cope with future situations.

Some of an agent's habits are "outgrowths of unlearned activities which are part of man's endowment at birth" (Dewey 1922/1988: 65). In other words, there are unlearned habits that are innate, but that does not mean that those habits simply emerge spontaneously. An environment is necessary for them to emerge. In the case of social agents, like human beings, the medium is social: "They are habits formed under the influence of association with others who have habits already and who show their habits in the treatment which converts a blind physical discharge into a significant anger" (ibid.: 66). Popp suggests that if Dewey had known the notion of a genome, he would have used it to explain the formation of habits (Popp 2012: 42).

However, agents can also have some control over problematic situations. Some agents can learn, so they can gain the ability to assure their future in the present. They do so by means of "reflective intelligence":

A being which can use given and finished facts as signs of things to come; which can take given things as evidences of absent things, can, in that degree, forecast the future; it can form reasonable expectation. It is capable of achieving ideas; it is possessed of intelligence. For use of the given or finished to anticipate the consequence of processes going on is precisely what is meant by "ideas," by "intelligence." [...] In the degree in which it can read future results in present ongoings, its responsive choice, its partiality to this condition or that, become intelligent. Its bias grows reasonable. It can deliberately, intentionally, participate in the direction of the course of affairs. (Dewey 1917/1998: 69)

Dewey's account of inquiry is based on the theory of evolution. Human beings are natural agents, and "the development of intelligence with respect to the control of human environments in order to effect increased meaning and significance within those environments is for Dewey emergent within nature" (Hickman 1990: 10). To the extent that human beings are just another species of animals, we acquire the ability to reason in the same way that we obtain the rest of our cognitive capacities: that is, naturally. To use Dewey's own turn of phrase, human beings have got nothing "out of the a priori blue."

Those capacities to control the environment, to deal with problematic situations, are also present in other species, but to different degrees. In fact, this can be inferred by "the principle of continuity": qualities such as emotions and needs are merely natural facts, and are the components of "qualitative thinking," different from the discursive way of thinking. However, discursive thinking is impossible without qualitative thinking. "A quality, an emotion, a need, and discursiveness, all these are equally natural phenomena, which go together in every process of experience; they are constituted in relation to each other, and are directed towards reaching new meaningful senses or meanings" (Stankiewicz 2011: 109).

21 As Gallagher (2014), and Cosmelli and Thompson (2010), among others, have pointed out, Dewey's characterization of cognition as the result of a dynamic interaction of the body and the environment is consistent with enactivist arguments that cognition is not just a matter of brain process, but that perception and thinking are fully integrated with motor action (Gallagher 2009, 2014). However, Dewey also emphasizes that human 
cognition is always socially situated - an observation which is usually left out in the enactive approach (Gallagher 2009: 39).

We see that man is somewhat more than a neatly dovetailed psychical machine who may be taken as an isolated individual, laid on the dissecting table of analysis and duly anatomized. We know that his life is bound up with the life of society, of the nation in the ethos and nomos; we know that he is closely connected with all the past by the lines of education, tradition, and heredity. (Dewey 1884: 278)

The relevance of the social environment cannot be omitted, from Dewey's point of view, insofar as we obtain practical knowledge from others, "watching them act, communicating with them, and learning from them through processes like imitation" (Gallagher 2009: 39). Those elaborate and complex communicative abilities of human beings make a substantial difference to other animals. In fact, it can be argued that the gap between the technology of humans and nonhuman animals is based precisely on those communicative and social capacities.

Dewey's interpretation of experience, situation, habits, and inquiry has many implications when it comes to technology. Dewey considered that "Technology" signifies all the intelligent techniques by which the energies of nature and man are directed and used in satisfaction of human needs. The creation of a new technology or a new tool arises from new situations: situations where the agent realizes that some familiar habit, technique, or tool has failed to work as usual. Then, the agent needs to inquire, producing a new solution: a new habit, a new technique, or a new tool that is more satisfactory than the previous one. For a new technological solution to appear, intelligence, in the form of inquiry, is always required. As Hickman points out: "that inquiry is a natural activity. He [Dewey] was naturalizing technology. He was telling us that technology is what we use to improve our tools and techniques - to tune them up" (Hickman 2001: 29-30).

Therefore, technology must be understood in a naturalized vein, and for that purpose, Dewey uses three concepts: "accommodation," "adaptation," and "adjustment" (also "growth" in other texts). Accommodation is the reaction of the agent to changes in the environment - to conditions that cannot be altered, such as changes in the weather. If those situations last, then the agent acquires a habit: "The two main traits of this attitude, which I should like to call accommodation, are that it affects particular modes of conduct, not the entire self, and that the process is mainly passive" (Dewey 1934/1989: 12). The agent may have a more active reaction and, instead of accommodating him or herself, modify the conditions, changing the situation to accommodate (i.e. to adapt) them to the agent's own purposes. This is what Dewey understands as adaptation. Adjustment occurs when there are changes also in the agents, and those changes are the result of changes in the world. "They relate not to this and that want in relation to this and that condition of our surroundings, but pertain to our being in its entirety. Because of their scope, this modification of ourselves is enduring [...]. It is a change of will conceived as the organic plenitude of our being, rather than any special change in will" (ibid.: 12-3). Therefore, accommodation occurs in both ways: the world changes (accommodates) by the action of agents, adapting environmental conditions to their needs; and the agent changes (adjusts) to environmental conditions.

Dewey identifies the inquiry involved in those activities and equates it with technology. Some living beings use mediating objects - tools to bring about adaptation. This "naturalization of technology" can be easily applied to agents other than humans. "It is 
not something above or apart from nature, but rather the cutting edge of evolutionary development" (Hickman 2009: 51).

Viewed as a part of a larger picture, habits are tools of adjustment. A habit is something that has a certain generality of application. It is something that has been tried out and found to be capable of serving certain purposes. Viewed from this perspective, as habits of a sort, hammers and saws become continuous with the other habits developed over millennia by higher order primates, for example, in their attempts to adjust to changing environmental conditions. Viewed in this perspective, to say that human beings are uniquely technological animals is not to place them outside and above nature, but within nature and a part of it. Our activities differ from those of our non-human relatives and ancestors not in kind, but only in level of complexity. (Ibid.: 52)

The connection between perception and action in the formation of habits is not exclusive to human agents. Actually, if the notion of habit also encompasses those actions that are part of innate behavior, then every living being experiences and is part of the environment. The principle of continuity, applied to all living beings, provides a framework to explain gradual differences in capabilities and kinds of actions and habits.

Before making use of Dewey's notions for other animals, it might be useful to briefly summarize the main approaches of contemporary ethology on this topic and the few philosophers who have suggested an interpretation for the technical abilities of nonhuman animals.

\section{Nonhuman Technical Capacities as Viewed in Ethology and Philosophy}

Technical abilities of nonhuman animals have been analyzed in ethology under the umbrella of "tool use." A great many field and laboratory studies have been conducted to analyze other animals' abilities to create and use tools. In philosophy of technology, there are a few exceptions that take these abilities into account. Among those exceptions, the contributions of Beth Preston (1998), and more recently, Ashley Shew (2017) stand out.

There are several definitions and classifications of "tool use" in ethology. All of them agree that tools must be external objects to the nonhuman animal that uses the object, avoiding the inclusion of an animal's use of its own organ in the category (Boswall 1977a, 1977b, 1978, 1983, and Beck 1980). Most definitions also agree that the object has to be dynamic (Van Lawick-Goodall 1970: 195; Alcock 1972: 464; St Amant \& Horton 2008: 1203; Bentley-Condit \& Smith 2010; Schumaker, Walkup \& Beck 2011: 5): i.e. dynamically used by the animal. Nevertheless, those who want to include things like birds' or insects' nests do not agree with this restriction (Pierce 1986: 96). Likewise, there is a general agreement that those objects internally produced, like spiders' webs, or silkworms' cocoons, cannot be considered tools stricto sensu (only Gould 2007 hold otherwise).

30 There is more agreement about the definition of "tool manufacture." Schumaker, Walkup and Beck define "tool manufacture" as "simply any structural modification of an object or an existing tool so that the object serves, or serves more effectively, as a tool. [...] Modification means alteration of the dimensional physical characteristics of 
the tool, not simply its spatial orientation" (Schumaker, Walkup \& Beck 2011: 11). They list four types of tool manufacture: detach, subtract, add/combine and reshape.

The two most extensive classifications of tool use have been proposed by BentleyCondit and Smith (2009) and Shumaker, Walkup and Beck (2011). Bentley-Condit and Smith (2009: 190-1) suggest a classification of tool use in ten categories, distinguishing between different activities that can be performed with those tools. Likewise, Shumaker, Walkup, and Beck suggest a classification based on a functional argument, but their classification is broader, including 22 types of actions that animals can perform.

In ethology, tools are classified according to the "function" that nonhuman animals can perform with them, and subsequently according to their shape, structure, or any other physical characteristic. To avoid the charge of anthropomorphism, all of them avoid using "intentions behind the actions" that nonhuman animals perform with those objects. There is a long tradition in nonhuman animal behavior studies of exercising great caution about using the same kind of explanations for human behavior and nonhuman animals' behavior. The claim that anthropomorphism is a fallacy was made in order to identify and root out anecdotalism (like when Darwin and Romanes were trying to establish the continuity of human and nonhuman traits and suggested that some nonhuman traits should be understood using traits that humans have). Anthropomorphism is defined as "the attribution of human traits, specifically human psychological traits, to non-humans" (Fitzpatrick 2008: 235), or more precisely "the attribution of human psychological, social, or normative properties to non-human animals" (Andrews \& Huss 2014: 711). However, in principle, there is nothing wrong with attributing human properties to nonhuman animals. As Keeley (2004) has pointed out "we simply cannot know a priori whether a given human trait is or is not uniquely human, or whether a given species shares any human traits" (Keeley 2004: 533). In the same vein, Fitzpatrick points out that "This [anthropomorphism] in itself, is not a mistake, since humans surely do share many psychological traits with other species" (Fitzpatrick 2008: 235). The problem arises when human psychological characteristics are attributed to nonhuman animals with a lack of supporting evidence - i.e. when it is possible to maintain a non-anthropomorphic explanation better supported by evidence.

Beth Preston (1998) was the first philosopher to consider those definitions of "tools" and "tool use" conventionally used among ethologists, and suggests a different theoretical framework, based on Martin Heidegger's notion of equipment (Zeug) as a substitute for what she considers "folk categories." Heidegger strongly opposes the distinction between subject and object that comes from the Cartesian tradition, and believes that some mental capabilities such as intentionality or representation bridge the gap between subject and object. From Heidegger's perspective, the subject-object relationship has to be understood in terms of being-in-the-world. Being is divided into two: human-being (Dasein), and non-human being. Non-human being, in turn, is divided into Zuhandenheit and Vorhandenheit, "readiness-at-hand" and "presence-at-hand" respectively, and Zeug. The latter is a special category referring to those things that humans encounter in everyday practical activities, like the tools or materials that we often refer to as "equipment." Equipment is constituted functionally, it is a useful thing, and it is used in order to get something done. In order for an object to actually function as a useful thing, it has to fit into the context of a meaningful activity. The 
English translation of Heidegger's term for such fitting [Bewandtnis] is involvement: objects have an involvement with other objects. Things are classed as equipment on the basis of their functionality. Therefore, functionality is a defining feature of equipment, and equipment is what it is only when actually used.

Function can only be understood through manipulation. The actual use of the equipment results in first-hand understanding of it. However, Heidegger also suggested a second-hand understanding of the equipment, when other human beings, even if they are not users of the equipment, know its public characteristics: "his [Heidegger's] analysis of equipmentality explicates equipment in terms of function, and function in terms of cultural norms of behaviour instituted by the "they"' (Preston 1998: 538). Therefore, "even though the functioning of a piece of equipment becomes available through manipulation, our understanding of equipment also depends on social norms and conventions for how things are normally used" (Susi \& Ziemke 2005: 10).

Preston is aware that applying Heidegger's proposal about equipment to nonhuman animals presents some difficulties. First of all, Heidegger's Dasein refers only to human beings (or, at least, to beings with our mental capacities), and sets aside (in a lower category) stones, plants, and nonhuman animals. Secondly, the "they" responsible for cultural norms are other human beings. Even today, the idea that a nonhuman animal culture exists is controversial, but in Heidegger's works, it is not even a possibility. However, Preston believes Heidegger's notion of equipment can also be applied to the case of other animals, because the difference between humans and nonhuman animals is a matter of degree, rather than an absolute difference (Preston 1998: 537-8). On the subject of norms, Preston points out that philosophers and scientists in biology and the behavioral sciences often use the concept of function, which is a normative term.

Another exception to the oblivion in philosophy about the technological capabilities of nonhuman animal is the recent book by Ashley Shew (2017). Shew holds that categories like culture, intelligence, and planning are not unique to humans. Her goal is to provide an explanation for some behaviors and capabilities that, from her point of view, fit under the umbrella of technological knowledge. In this sense, Shew develops an "epistemology of technology" that considers some of the actions and products of nonhuman animals as technological in character (Shew 2017: 1). Therefore, her claim is more epistemological than ontological: technological knowledge includes, in her account, nonhuman animal tool making and tool use. Additionally, Shew argues that "many cases of animal artifact-use evince the same qualities that define human technology use: planning, problem-solving, design, and innovation" (ibid.: 2).

Instead of using just one philosophical account of technology, as Preston does, Shew uses several approaches: the epistemological, the anthropological, and the sociological (in Mitcham's terms, see Mackey 1972). Shew examines those approaches for guidance in distinguishing between simple tool use, tool manufacture, and the use of technology.

Technological knowledge has two dimensions: know-how - a kind of knowledge that requires skills - and encapsulated information - in Davis Baird's terms (2002, 2004), thing knowledge, knowledge that is encapsulated in technology or in a device, and that may or may not have a theoretical counterpart. With this two-axis map, Shew considers that "we can actually unite discussions of design and function happening in both biology and engineering" (Shew 2017: 116).

On the one hand, the map allows us to explain the capacities of groups of nonhuman animals well known in the literature for using and making tools: chimpanzees, 
bottlenose dolphins, or New Caledonian crows. On the other, it allows us to classify particular nonhuman animal products from the perspective of thing knowledge: spider webs, beaver dams, and other nonhuman animal constructions.

Both approaches have great merit, raising their voices in philosophy of technology, which focuses mainly on human capacities and creations. Their points of view are not opposite, but account for nonhuman technical capacities in two different realms: the ontological, and the epistemological. The Heideggerian notion of equipment may be an interesting starting point. However, sensu stricto, it can be too narrow for explaining nonhuman creations. On the other hand, the distinction between know-how and thing knowledge is closely connected with human capabilities for representing and making knowledge explicit. In the next section, I will explore extending Dewey's notions of experience, habit, problematic situation, adaptation, and accommodation to nonhuman agents. Considering his enactivist and naturalist perspective, it is quite likely that if Dewey had known what ethology is telling us about nonhuman animal behavior, he would have extended his notions to other animals as well.

\section{Venturing a Pragmatist Interpretation of Nonhuman Animals' Technical Capacities}

41 Using Dewey's terms, we can say that all animals inhabit the same world, but they experience different environments, different situations, and modify them in different ways, depending on their approach to the problematic situation, as well as their physical and cognitive capabilities. For instance, dolphins experience very different environments from the environment experienced by New Caledonian crows, and therefore face different problematic situations. For one, dolphins, which live in aquatic environments, have the capacity to echo-localize, as well as a flexible and social way of learning. Since dolphins do not have hands, they use their mouths and flippers to manipulate the environment, such as when they select and put on their rostrum sponges from the seabed, for protection as they forage in the coarse sand (Krützen et al. 2005). Dolphins' habits will depend on these factors: the environment they inhabit (aquatic), their physical structure (they do not have hands, but they use their toothed beaks or their tails to manipulate their environment), and their cognitive and social capabilities (they are very intelligent animals, with brains among the largest in the animal kingdom, and they live in very intricate social organizations). New Caledonian crows, meanwhile, live in a terrestrial and aerial environment. They do not have hands either, but use their beaks to manipulate the environment and deal with their specific situations, like pulling worms out of the trees. Some of them have learned some of these strategies through social learning, but others are also able to find new solutions for themselves. Therefore, the environment plus the animal's capacities, both physical and cognitive, must be analyzed together to understand how different species use and manipulate artifacts in different ways.

Some problematic situations are solved with the adaptation of the environment to the necessities of the animal through the creation of an artifact (e.g. a nest), but others are solved in a more passive way with an accommodation to new circumstances: a new habit (for instance, trying a new kind of food), or modification of an old one (like foraging in a different place). When agents change in the long term as a result of these adaptations, in evolutionary terms, and also in Dewey's terms, adjustments occur. It may be 
debatable that specific agents change, and it would be better to refer to adjustment as species-wide changes, or in other words, evolution of the species (Figure 1).

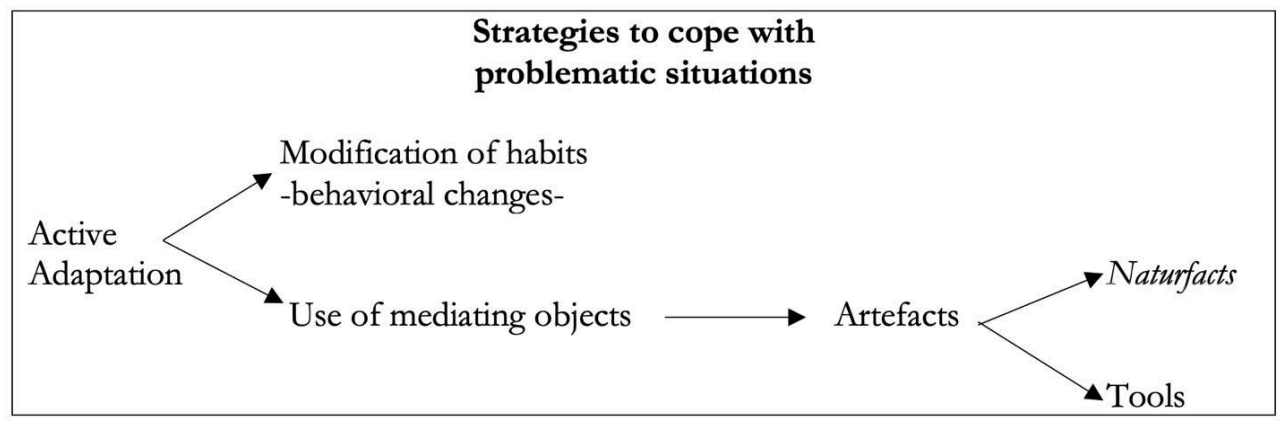

Figure 1

Those problematic and particular situations that are solved with an active adaptation can lead to different kinds of solutions, some of which can be achieved through modification of habits (such as behavioral changes in foraging times, or looking for new places to rest or hide). In some cases, however, animals can use mediating objects to find a solution for the problematic situation. Of course, not every mediating object used by an agent is necessarily an artifact (for example, water is an object used to quench the thirst, and also for cleaning, but it is not always necessarily an artifact). An artifact could be defined as an extreme case of a mediating object created or used to solve a problematic situation in an efficient way. Sometimes the object already exists, and it is picked out from among other natural objects for its special structure (Oswalt 1973, refers to them as naturfacts) - a structure that is identified by the animal for its outstanding features for solving the problematic situation. Take, for example, the stones that sea otters (Enhydra lutris) put on their thorax to open mollusks like mussels (observed by Hall \& Schaller in 1964), or the rocks used as an anvil for opening cockleshells by blackspot tuskfish (Choerodon schoenleinii) (Jones, Brown \& Gardner 2011: 865). Yet, in other cases, the object does not exist before, and the agent creates it, either by modifying natural objects, ${ }^{1}$ or by combining and assembling different natural objects. ${ }^{2}$ The structure of the object allows the animal to deal with the problematic situation, transforming it into a non-problematic one.

On the other hand, it might be useful to distinguish between different technical solutions based on behavioral flexibility to develop those solutions (Figure 2). On one extreme, there are unlearned habits displayed in an inflexible way. Some nonhuman animals exhibit innate dispositions to transform the environment by making objects: for instance, spiders' webs or butterflies' silk cocoons. A salient feature of these objects is that they are made always in the same way - i.e. the nonhuman animal cannot modify or improve them. Another step in the continuous spectrum of material solutions created by nonhuman animals are those objects, like birds' nests, which can be enhanced through experience and learning capabilities. Those improvements can be made to the structure, materials, strength, or other qualities of the object. However, they still largely depend on the innate dispositions of the nonhuman animal. In that sense, those nonhuman animals will create the object as part of their extended phenotype (Dawkins 1982). The animal could not survive or reproduce unless they fabricate those objects. However, animals learn by trial and error and have the capacity to introduce some variations into future objects based on past experiences. 


\begin{tabular}{|c|c|c|c|}
\hline \multicolumn{4}{|c|}{ Accumulative Behavioral Flexibility } \\
\hline $\begin{array}{l}\text { Innate habits: } \\
\text { displayed in an } \\
\text { inflexible way }\end{array}$ & $\begin{array}{l}\text { Innate but } \\
\text { changed and } \\
\text { improved habits } \\
\text { through trial and } \\
\text { error learning } \\
\text { strategies }\end{array}$ & $\begin{array}{l}\text { Reflective intelligence: } \\
\text { Anticipation, social } \\
\text { learning (imitate other } \\
\text { group members), } \\
\text { planning ahead }\end{array}$ & $\begin{array}{l}\text { Cultural learning and } \\
\text { "ratchet effect" }\end{array}$ \\
\hline $\begin{array}{l}\text { E.g. Behavior like } \\
\text { Spiders making } \\
\text { their webs or } \\
\text { butterflies silk } \\
\text { cocoons }\end{array}$ & $\begin{array}{l}\text { E.g. Behavior of } \\
\text { Hornero birds } \\
\text { (Furnarius rufus) in } \\
\text { the construction } \\
\text { of their nests, or } \\
\text { the behavior of } \\
\text { Beavers in the } \\
\text { construction of } \\
\text { the pond and } \\
\text { their shelter }\end{array}$ & $\begin{array}{l}\text { E.g. Chimps learn from } \\
\text { conspecifics how to } \\
\text { make and use leaf } \\
\text { sponges to collect water } \\
\text { and drink. Capuchin } \\
\text { monkeys save their } \\
\text { anvils and hammers for } \\
\text { future use. New } \\
\text { Caledonian crows } \\
\text { modifying small } \\
\text { branches or leaves for } \\
\text { making a hook to probe } \\
\text { them into holes in logs } \\
\text { to extract insects } \\
\text { and larvae }\end{array}$ & $\begin{array}{l}\text { Almost all technological } \\
\text { artifact manufactured by } \\
\text { human beings }\end{array}$ \\
\hline
\end{tabular}

Figure 2

Near the end of the spectrum would be artifacts created using what Dewey calls reflective intelligence. In these cases, nonhuman animals show capacities such as anticipation, and social learning. The main difference between the solutions based on reflective intelligence and those achieved in other artefact-based ways of dealing with problematic situations lies in the outstanding creativity involved in the former. Those nonhuman animals can find new solutions, learn by imitation of other group members, and even plan ahead, collecting previously used objects for future problematic situations (though not all members of these species find the same solution to the same kind of problem). So far, the group of species that ethologists have identified as possessing these capacities is quite small, including chimpanzees, orangutans, New Caledonian crows, woodpecker finches, and capuchin monkeys (Hunt 1996, 2000; Hunt \& Gray 2002, 2003; Boesch, Head \& Robbins 2009; Fragasz et al. 2004; Visalberghi \& Fragaszy 2009; Tebbich et al. 2001).

Human beings have exceptional capabilities that result in highly complex technology. Some authors have pointed out among those exceptional capabilities: (i) the ability to reason in terms of non-observable and/or hidden causes (Waldmann \& Hagmayer 2005; Kushnir et al. 2005; Saxe \& Wexler 2005), (ii) the ability to distinguish between "genuine" and "spurious" causes (Lien \& Cheng 2000); (iii) the ability to reason the link between the effects and their possible causes (Waldmann \& Holyoak 1992) and planning their own interventions in a quasi-experimental way to elucidate ambiguous causal relationships (Hagmayer et al. 2007). In addition, human beings develop "cultural learning" - a strategy different from social learning, as human culture is the only one dependent on teaching and imitation, together with language and perspective taking (Tomasello 1994). In the case of cultural learning, an individual human invents something at a certain time, another learns how to do it, and then modifies and improves it. Later, a new generation learns the new and improved version, and the 
improvement process starts again - and so on through generations (Tomasello 2000: 38). In the case of social learning - a capacity shown by many other species - animals learn by imitation in the presence of a conspecific. In contrast, in the case of cultural learning, the human being is able to make an interpretation of the function of the artifact without the presence of the inventor or the manufacturer, and also change that function, improving the original artifact or making a new one based on the old. Michael Tomasello has called this effect the ratchet effect, and it seems to be unique to humans: "some individual or group of individuals first invented a primitive version of the artifact or practice, and then some later user or users made a modification, an improvement, that others then adopted perhaps without change for many generations, at which point some other individual or group of individuals made another modification, which was then learned and used by others, and so on over historical time in what has sometimes been dubbed 'the ratchet effect"' (Tomasello 1999: 5). The process of accumulative cultural evolution requires not only creative invention but also, and most importantly, a faithful social transmission that can function as a ratchet to prevent slipping back. Newly invented artifacts or practices continue in their new and improved form until a new modification or improvement arrives (Tomasello 2000: 5). Therefore, social transmission - that is, the communicative and social capacities of the human being, including the immense variety of artifacts (technological, social or artistic) - has led to an enormous change. This conclusion is consistent with Dewey's emphasis on the social condition of human cognition. In Dewey's own words: “All inquiry proceeds within a cultural matrix which is ultimately determined by the nature of social relations. [...] The techniques available at any given time depend upon the state of material and intellectual culture" (Dewey 1938/1991: 487). Dewey also applied these ideas in his pedagogical theory and in his consideration of the construction of scientific knowledge.

In summary, each animal has to deal with its own environment, its own problematic situations, with its specific physical and cognitive capacities. Every species inhabits a specific environment, but copes with it in different ways. In their interaction, the environment and the species both change. In some cases, changes are manifested using objects available in the environment, and in other cases those changes require the creation of a new object - an object that is the outcome of the purposeful manipulation of the environment. Human strategies to adapt to the environment are more complex than those used by other species, which is not to say that human strategies do not also arise from natural and evolved capacities. Dewey's notions of experience, problematic situation, habit and inquiry, adjustment and adaptation are broad enough to include not just human beings, but also other agents, avoiding anthropocentric explanations that set human capabilities apart from those of other animals.

\section{Conclusions}

In this paper, I have explored a different approach for explaining technical capabilities of nonhuman animals. Traditionally, humans have been distinguished by their unique abilities. However, new scientific research shows that humans are not as unique as we thought.

Using an enactivist approach can be very useful to understand that living beings inhabit the world and cope with their challenges in different ways, depending on their 
physical, structural, cognitive, or social characteristics. Some animals have the ability to transform their environment, creating new objects to solve their difficulties: objects that fit into the category of technical artifacts.

Here, I have explored the possibility of employing several of Dewey's notions to account for nonhuman technical capabilities. His non-dichotomous perspective, his vindication of the theory of evolution, and his considerations about artifacts may be helpful in understanding that human technical capabilities are simply different in degree from those of nonhuman animals. Another scientific approach that can be analyzed in Dewey's terms is the Niche construction perspective (Lewontin 1982, 2000, and more recently Odling-Smee, Laland \& Feldman 2013). However, this deserves its own analysis: one that I wish to develop in depth in future works.

\section{BIBLIOGRAPHY}

ALCOCK John, (1972), “The evolution of the use of tools by feeding animals," Evolution, 26, 464-73.

ANDREWS Kristin \& Brian HUSS, (2014), "Anthropomorphism, anthropectomy, and the null

hypothesis," Biology \& Philosophy, 29 (5), 711-29.

BAIRD Davis, (2002), “Thing knowledge-function and truth,” Techne: Research in Philosophy and

Technology, 6 (2), 96-105.

BAIRD Davis, (2004), Thing Knowledge: A Philosophy of Scientific Instruments, Berkeley, University of California Press.

BECK Benjamin B., (1980), Animal Tool Behavior, Garland STPM Pub.

BENTLEY-CONDIT Vicky K. \& E. O. SMITH, (2010), “Animal tool use: current definitions and an updated comprehensive catalog," Behaviour, 147 (2), 185-221.

BOESCH Christophe \& Hedwige BOESCH, (1990), "Tool use and tool making in wild chimpanzees," Folia primatologica, 54 (1-2), 86-99.

BOESCH Christophe, HEAD Josephine \& Martha. M. ROBBINS, (2009), “Complex tool sets for honey extraction among chimpanzees in Loango National Park, Gabon," Journal of Human Evolution, 56 (6), 560-9.

BOSWALL Jeffrey, (1977a), “Tool using by birds and related behaviour,” Aviculture Maazine, 83, 88-97.

BOSWALl Jeffrey, (1977b), “Notes on tool-using by Egyptian Vultures," Bulletin of the British Ornithologists' Club, 14 (2), 74-6.

BOSWALL Jeffrey, (1978), "Further notes on tool-using by birds and related behaviour," Aviculture Magazine, 8, 162.

BOSWALL Jeffrey, (1983), “Tool-using and related behaviour in birds: More notes," Aviculture Magazine, 89, 94-108. 
BREEN Alexis, GUILLETTE Lauren M. \& Susan D. HEALY, (2016), “What can nest-building birds teach us?," Comparative Cognition \& Behavior Reviews, 11, 83-102.

COSMELLI Diego \& Evan THOMPSON, (2010), "Embodiment or envatment? Reflections on the bodily basis of consciousness," in H. De Jaegher \& M. Rohde (eds), Enaction: Towards a new paradigm for cognitive science, Cambridge, Mass., MIT Press, 361-85.

DAWKINS Richard, (1982), The Extended Phenotype, Oxford, Oxford University Press

DEWEY John, (1884), “The new psychology,” Andover Review, 2, 278-89. Online: (https:// psychclassics.yorku.ca/Dewey/newpsych.htm) (Retrieved 30 October, 2020).

DEWEY John, (1917/1998), “The Need for a Recovery of Philosophy,” in Larry A. Hickman \& Thomas M. Alexander (eds), The Essential Dewey, Bloomington and Indianapolis, Indiana University Press. DEWEY John, (1922/1988), "Human Nature and Conduct," in The Collected Works of John Dewey, 1882-1953, Middle Works, Volume 14: 1922, ed. Jo Ann Boydston, Carbondale and Edwardsville, Southern Illinois University Press.

DEWEY John, (1938/1991), Logic, the theory of inquiry, in The Collected Works of John Dewey, 1925-1953, The Later Works of John Dewey, vol. 12, 1938, ed. Jo Ann Boydston, Carbondale and Edwardsville, Southern Illinois University Press.

DEWEY John, (1989), “A Common Faith,” in The Collected Works of John Dewey, 1933-1934, The Later Works of John Dewey, vol. 9, 1934, ed. Jo Ann Boydston, Carbondale and Edwardsville, Southern Illinois University Press.

DEWEY John, (1934/2005), Art as Experience, New York, Milton, Balch.

FABBRICHESI Rossella, (2016), "Peirce, Mead, and the theory of extended mind," in M. Bergman, \& J. Queiroz (eds), The Commens Encyclopedia: The Digital Encyclopedia of Peirce Studies, New Edition Pub, 161125-0957a.

FITZPATRICK Simon, (2008), “Doing away with Morgan's Canon,” Mind \& Language, 23 (2), 224-46.

FRAGASZY Dorothy, IZAR Patricia, VISALBERGHI Elisabetta, otTONI Eduardo B. \& Marcio G. DE OLIVEIRA, (2004), "Wild capuchin monkeys (Cebus libidinosus) use anvils and stone pounding tools," American Journal of Primatology: Official Journal of the American Society of Primatologists, 64 (4), 359-66.

GALLAGHER Shaun, (2009), "Philosophical antecedents of situated cognition," in P. Robbins \& M. Aydede (eds), Cambridge Handbook of Situated Cognition, Cambridge, Cambridge University Press, 35-51.

GALLAGHER Shaun, (2014), "Pragmatic interventions into enactive and extended conceptions of cognition," Philosophical Issues, 24 (1), 110-26.

GALLAGHER Shaun, (2017), Enactivist Interventions: Rethinking the Mind, Oxford, Oxford University Press.

GLOCK Hans Johann, (2008), “Post scríptum II,” in Id. (ed.), La mente de los animales: problemas conceptuales, Oviedo, KRK.

GOULD James L., (2007), “Animal artifacts,” in Eric Margolis, \& Stephen Laurence (eds), Creations of the Mind: Theories of Artifacts and their Representation, Oxford, Oxford University Press, 249-66.

HAGMAYER York, SLOMAN Steven A., LAGNADo David A. \& Michael R. WALDMANN, (2007), “Causal reasoning through intervention," Causal Learning: Psychology, Philosophy, and Computation, 86-100. 
HALL K. R. L. \& George B. SCHALLER, (1964), “Tool-using behavior of the California sea otter,” Journal of Mammalogy, 45 (2), 287-98.

HICKMAN Larry A., (1990), John Dewey's Pragmatic Technology, Bloomington, Indiana University Press.

HICKMAN Larry A., (2001), Philosophical Tools for Technological Culture: Putting Pragmatism to Work, Bloomington, Indiana University Press.

HICKMAN Larry A., (2009), “John Dewey as a philosopher of technology,” Readings in the Philosophy of Technology, 43, 43-55.

HUNT Gavin R., (1996), "Manufacture and use of hook-tools by New Caledonian crows," Nature, 379 (6562), 249-51.

HUNT Gavin R., (2000), "Human-like, population-level specialization in the manufacture of pandanus tools by new Caledonian crows corvus moneduloides," Proceedings of the Royal Society of London. Series B: Biological Sciences, 267 (1441), 403-13.

HUNT Gavin R. \& Russell D. GRAY, (2002), "Species-wide manufacture of stick-type tools by New Caledonian crows," Emu, 102 (4), 349-53.

HUNT Gavin R. \& Russell D. GRAY, (2003), "Diversification and cumulative evolution in New Caledonian crow tool manufacture," Proceedings of the Royal Society of London. Series B: Biological Sciences, 270 (1517), 867-74.

HUNT Gavin R. \& Russell D. GRAY, (2004), "The crafting of hook tools by wild New Caledonian crows," Proceedings of the Royal Society of London. Series B: Biological Sciences, 271 (suppl.3), 88-90. IHDE Don, (1990), Technology and the Lifeworld: From Garden to Earth, Bloomington, Indiana University Press.

IHDE Don, (2009), Postphenomenology and Technoscience: the Peking University Lectures, New York, SUNY Press.

IHDE Don \& Lambros MALAFouRIS, (2019), “Homo faber revisited: Postphenomenology and material engagement theory," Philosophy \& technology, 32 (2), 195-214.

JONES Alison M., BROWN Culum \& S. GARDNER, (2011), “Tool use in the tuskfish choerodon schoenleinii?," Coral Reefs-Journal of the International Society for Reef Studies, 30 (3), 865.

KALPOKAS Daniel, (2010), “Dewey y el mito de lo dado,” Éndoxa: Series Filosóficas, 26, 157-86.

KEELEY Brian L., (2004), “Anthropomorphism, primatomorphism, mammalomorphism: understanding cross-species comparisons," Biology and Philosophy, 19 (4), 521-40.

KRÜTZEN Michael, MANN Janet, HEITHAUS Michael R., CONNOR Richard C., BEJDER Lars \& William B. SHERWIN, (2005), "Cultural transmission of tool use in bottlenose dolphins," Proceedings of the National Academy of Sciences, 102 (25), 8939-43.

KUSHNIR Tamar \& Alison GOPNIK, (2005), "Young children infer causal strength from probabilities and interventions," Psychological science, 16 (9), 678-83.

LEWONTIN Richard C., (1982), "Organism and environment," in H. C. Plotkin (ed.), Learning, Development and Culture, New York, Wiley, 151-70.

LEWONTIN Richard C., (2000), The Triple Helix: Gene, Organism, and Environment, Cambridge, Mass., Harvard University Press. 
LIEN Yunnwen \& Patricia W. CHENG, (2000), "Distinguishing genuine from spurious causes: A coherence hypothesis," Cognitive Psychology, 40 (2), 87-137.

MÄÄTTÄNEN Pentti, (2015), Mind in Action: Experience and Embodied Cognition in Pragmatism, vol. 18, New York, Springer.

MALAFOURIS Lambros, (2008), "Between brains, bodies and things: tectonoetic awareness and the extended self," Philosophical Transactions of the Royal Society of London Series B, (363), 1993-2002.

MALAFOURIS Lambros, (2014), "Creative thinging: the feeling of and for clay," Pragmatics and Cognition, 22 (1), 140-58.

MALAFOURIS Lambros, (2015), "Metaplasticity and the primacy of material engagement," Time and Mind, 8 (4), 351-71.

MACKEY Robert, (1972), Philosophy and Technology. Readings in the Philosophical Problems of Technology, New York, The Free Press.

ODLING-SMEE F. John, LALAND Kevin N. \& Marcus W. fELDMAN, (2013), Niche Construction: The Neglected Process in Evolution (MPB-37), vol. 37, Princeton, Princeton University Press.

osWaLT Wendell H., (1972), Habitat and Technology: The Evolution of Hunting, Holt, Rinehart and Winston.

PEARCE Trevor, (2020), Pragmatism's Evolution: Organism and Environment in American Philosophy, Chicago, University of Chicago Press.

PIERCE Jr. John D., (1986), “A review of tool use in insects,” Florida Entomologist, 69 (1), 95-104.

POPP Jerome A., (2012), Evolution's First Philosopher: John Dewey and the Continuity of Nature, New York, SUNY Press.

PRESTON Beth, (1998), “Cognition and tool use,” Mind and Language, 13 (4), 513-47.

SAXE Rebecca \& Anna WEXLER, (2005), "Making sense of another mind: the role of the right temporo-parietal junction," Neuropsychologia, 43 (10), 1391-9.

SHUMAKER Robert W., WALKUP Kristina R. \& Benjamin B. BECK, (2011), Animal Tool Behavior: The Use and Manufacture of Tools by Animals, Baltimore, Maryland, JHU Press.

SHEW Ashley, (2017), Animal Constructions and Technological Knowledge, Lexington Books.

ST AMANT Robert \& Thomas E. HORTON, (2008), "Revisiting the Definition of Animal Tool Use," Animal Behaviour, 75 (4), 1199-208.

STANKIEWICZ Sebastian, (2011), "Qualitative thought, thinking through the body, and embodied thinking: Dewey and his successors," in Larry Hickman (ed.), The Continuing Relevance of John Dewey. Reflections on Aesthetics, Morality, Science, and Society, Brill Rodopi, 101-18.

SUSI Tarja \& Tom ZIEMKE, (2005), “On the subject of objects: Four views on object perception and tool use. tripleC: Communication, Capitalism \& Critique," Open Access Journal for a Global Sustainable Information Society, 3 (2), 6-19.

TEBBICH Sabine \& Redouan BSHARY, (2004), "Cognitive abilities related to tool use in the woodpecker finch, Cactospiza pallida," Animal behaviour, 67 (4), 689-97.

TEBBICH Sabine, TABORSKY Michael, fESSL Birgir \& Donald BLOMQVIST, (2001), "Do woodpecker finches acquire tool-use by social learning?," Proceedings of the Royal Society of London. Series B: Biological Sciences, 268 (1482), 2189-93. 
TOMASELlo Michael, (1994), "The question of chimpanzee culture," in R. Wrangham, W. McGrew, F. de Waal \& P. Heltne (eds), Chimpanzee Cultures, Cambridge, Mass., Harvard University Press, 301-17.

TOMASELlo Michael, (1999), The Cultural Origins of Human Cognition, Cambridge, Mass., Harvard University Press.

TOMASEllo Michael, (2000), "Culture and cognitive development," Current Directions in Psychological Science, 9 (2), 37-40.

VAN LAWICK-GOODAL Jane, (1970), "Tool-using in primates and other vertebrates," Advances in the Study of Behavior, 3, 195-249.

VAN SCHAIK Carel P., FOX Elizabeth A. \& Arnold F. SITOMPUL, (1996), "Manufacture and use of tools in wild Sumatran orangutans," Naturwissenschaften, 83 (4), 186-8.

VISALBERGHI Elisabetta \& Dorothy FRAGASzY, (2013), "The Etho-Cebus Project: Stone-tool use by wild capuchin monkeys," in Crickette M. Sanz, Josep Call \& Christophe Boesch (eds), Tool Use in Animals: Cognition and Ecology, Cambridge, UK, Cambridge University Press, 203-22.

WALDMANN Michael R. \& Keith J. HOLYOAK, (1992), "Predictive and diagnostic learning within causal models: asymmetries in cue competition," Journal of Experimental Psychology: General, 121 (2), 222-36.

WALDMANN Michael R. \& York HAGMAYER, (2005), "Seeing versus doing: two modes of accessing causal knowledge," Journal of Experimental Psychology: Learning, Memory, and Cognition, 31 (2), 216-27.

WILSON Edward O., (1975), Sociobiology: The New Synthesis, Cambridge, Mass., Belknap Press.

\section{NOTES}

1. Until now, ethologists have identified four species of nonhuman animals that can manufacture tools: chimpanzees (Pan troglodites), orangutans (Pongo pygmaeus), New Caledonian Crows (Corvus moneduloides), and Woodpecker finches (Cactospiza pallida). Chimpanzees in the wild were observed making and using artifacts such as modified tree branches to fish termites, stone hammers and anvils, tree branches for dipping into honey, or leaf sponges for drinking water (Van Lawick-Goodal 1970; Boesch \& Boesh 1990). A population of Sumatran orangutan modify and use tree branches to access insects and Neesia seeds (a kind of fruit with a hard shell, coated with irritant hairs) (van Schaik, Fox \& Sitompul 1996). Crows of New Caledonia have the ability to make some objects to extract worms from bark trees. They select from among the branches and leaves of the trees and shape them three-dimensionally. They are able to perform these actions with a high level of standardization in manufacturing, high levels of skill in production and cumulative changes in the design of objects (Hunt \& Gray 2004). Woodpecker finches modify twigs and thorns to extract arthropods from holes or cracks in bark. They shape these objects, shortening or cleaning them of lateral branches that prevent proper and efficient use (Tebbich \& Bshary 2004). $50 \%$ of the food that they eat during the dry season is obtained by using these hooks.

2. Nests built by nonhuman animals include those built by birds and insects, as well as those made by mammals, amphibians, fish, reptiles, and spiders. Nests can involve the collaborative work of more than one agent and, in many cases, a large number of them. A few examples are: the hives of the honey bee (Apis mellifera), built by the workers of the colony, with complex internal structure (Pierce 1986: 100); and the nests of Macrotermes termites of Africa (Wilson 
1975). Among nonhuman animals, birds are probably the most impressive nest builders: "The techniques with which birds build their nests [...] range from the sculpting of burrows or cavities from substrate excavation, through the moulding of mud or salivary mucus by vibrating head and/or shaping breast and feet movements, the piling up of materials where subsequent bill manipulations, coupled with side-to-side shaking movements, may be made in order to entangle or intertwine nest components, to the weaving of hanging nest baskets using intricate tuck, looping, interlocking, winding, and knotting bill-made stitches to fasten and secure grassy materials" (Breen, Guillette \& Healy 2016: 84). Among mammals, beavers (genus Castor) modify the environment using huge logs, branches (which they themselves cut) and mud structures to dam streams and create ponds where they build their lodges, also built with branches and mud.

\section{ABSTRACTS}

Human technological capabilities have been analyzed as a distinctive feature of the species. However, recent discoveries in the field of ethology show that other species besides humans are also able to use and make tools. Ihde and Malafouris (2019) have suggested analyzing nonhuman animals' technical capabilities using an enactivist framework, as they do for humans. This paper explores a pragmatist approach, combining gradual evolutionary continuity with enactivism. I will characterize nonhuman animals' technical capacities using John Dewey's notions of experience, problematic situation, accommodation, adaptation, and inquiry. The technical capabilities of nonhuman animals are better explained in a non-dichotomic fashion, avoiding anthropocentric explanations.

\section{AUTHOR}

\section{ANA CUEVAS-BADALLO}

University of Salamanca, Spain

acuevas[at]usal.es 